\title{
Genetic engineering of a probiotic-based drug delivery system for colorectal cancer therapy
}

\author{
Byung Chull An, Yongku Ryu, Oksik Choi, Sunwoong Hong, Jin Young Heo and Myung Jun Chung* \\ R\&D Center, Cell Biotech, Co., Ltd., 50, Aegibong-ro 409 beon-gil, Gaegok-ri, Wolgot-myeon, Gimpo-si, Gyeonggi-do, Korea
}

\begin{abstract}
Food-grade bacteria, including lactic acid bacteria (LAB), are safe to ingest and are not associated with development of disease. The impact of LAB on health has been studied in depth from a clinical perspective. Evidence suggests that LAB benefit health in several ways, including improving the balance between probiotic and harmful bacteria in the intestine, protecting against pathogen infections, and modulating host immunity in the gut. Recent publications show that LAB are safe biotherapeutics that exert positive effects against various cancer types, including colorectal cancer (CRC). CRC develops in intestine and, unless treated early, will invade the surrounding tissue and spread to other parts of the body. One intrinsic advantage of food-grade LAB is that they can be applied easily as oral medications and act as vehicles for bio-therapeutics, which can be delivered directly to the mucosal surface of the intestine. Consequently, a LAB-based drug delivery system (DDS) can have synergistic effects: the patient derives benefit from both the LAB and the therapeutic cargo. Furthermore, the localized effect of LAB-based DDS in the intestine would ensure targeted treatment at the site of disease; this has the benefits of requiring a lower dose of a drug, with fewer systemic side effects. In this review, we discuss the evidence supporting the beneficial effects of LAB-based DDS and its application to CRC.
\end{abstract}

\section{Introduction}

\section{Benefits of LAB}

Lactic acid bacteria (LAB) and other probiotic bacteria are living supplementary organisms that are beneficial to the host; in addition, these bacteria are safe, with a history of use as a foodstuff going back thousands of years [1,2]. Two major advantages are their proven overall health benefits to the host and their potential as a vehicle for therapy [3]. Many studies have examined the role of the human gut microbiota; indeed, colonization of the gut by LAB provides balance and contributes to the health of the host [4]. A review by An et al. discusses recent insights into the cellular and molecular mechanisms underlying the beneficial effects of LAB; these mechanisms are related to cell cycle arrest, apoptosis, immune responses, inflammatory responses, antioxidant DNA damage, and epigenetics [5].

\section{Potential of LAB as an anti-cancer therapeutic}

As well as providing health benefits in their own right, LAB can also play a role in therapy [3]. Indeed, animal and preliminary human studies demonstrate the therapeutic effects of LAB in the context of various diseases, including cancer $[5,6]$. Recent studies show that LAB suppress growth of colon, stomach, breast, cervix, and myeloid leukemia cells via multiple pathways $[7,8]$. Thus, LAB-based regimens are often used as an adjuvant during anti-cancer chemotherapy. However, because orally administered LAB reside in the gastrointestinal tract and colonize the host intestine, they are likely to be most useful as therapeutics for gastrointestinal cancers; indeed, numerous animal studies show the positive anti-cancer effects of $\operatorname{LAB}[5,9,10]$. Colorectal cancer (CRC), which begins as a polyp, is the most common malignancy of the gastrointestinal tract and remains one of the most common causes of death worldwide [11]. However, LAB show promise as a means of preventing and suppressing progression of CRC [12]. Moreover, oral administration of LAB normalizes the balance within the intestinal microflora, improves the gastrointestinal barrier, inhibits the growth of potential pathogens, and suppresses carcinogenesis in the gut [5].

\section{Genetic engineering of LAB}

Recent studies raise the possibility of using LAB as bio-therapeutic agents to develop cutting-edge cancer therapies. Genetic engineering methods have allowed modification of LAB, particularly Lactococcus lactis (L. lactis) and others, for industrial or medical purposes [13]. Gene expression systems have been developed to facilitate genetic engineering of $\mathrm{LAB}$, thereby allowing controlled expression of target genes using various promoters that are regulated by sugar (the lactose operon promoter) [14] and salt (the gadC promoter) [15] concentrations, temperature upshifts (the tec phage promoter) [16], reduced $\mathrm{pH}(\mathrm{P} 170)$ [17], or phage infection (the phi31 promoter) [18]. Although promoter-inducible systems are not always easy to regulate, introduction of a well-characterized promoter might allow controlled expression of downstream genes and could be applied to diverse LAB species [19]. Future innovations regarding the therapeutic use of LAB are necessary to validate these improvements and establish reliable and safe therapeutic strategies. These challenges could lead to a medical breakthrough in the fields of immunotherapy and cancer treatment, as well as improve delivery of anti-inflammatory drugs to treat other bowel diseases.

Below, we discuss the genetic modification of LAB and their use as bio-therapeutic agents for cancer therapy. An important property

${ }^{\star}$ Correspondence to: Myung Jun Chung, Ph.D., R\&D Center, Cell Biotech, Co., Ltd., 50, Aegibong-ro 409 beon-gil, Gaegok-ri, Wolgot-myeon, Gimpo-si, Gyeonggi-do, Korea, E-mail: ceo@cellbiotech.com

Key words: lactic acid bacteria, drug delivery system, probiotics, colorectal cancer, bio-therapeutics, anti-cancer activity

Received: April 06, 2020; Accepted: April 16, 2020; Published: April 22, 2020 
of LAB is that they are regarded as "food-grade" because of their safe application as probiotics when compare with other bacteria.

\section{Plasmid vector systems}

Plasmids, diverse expression systems that harbor selective markers, allow expression and maintenance of exogenous molecules in the host. Plasmids for LAB contain a replication source from a natural plasmid combined with a food-grade selection marker [20-23]. Food-grade selection markers for $\mathrm{LAB}$ are divided into two groups: selectable markers that confer a new phenotype (such as sugar utilization or bacteriocin resistance) [24], and complementation markers (e.g., alanine racemase [25] and thymidylate synthase [26]) that restore an impaired function to promote cell viability. Although plasmid vector systems are versatile, they have several limitations, including copy number alteration, loss of selection markers, and poor stability [27].

\section{Chromosome modification systems}

Allelic replacement in the chromosome is a natural phenomenon that allows genetic modification or insertion of stable DNA into host chromosomes without leaving behind unnecessary foreign DNA. Allelic replacement occurs via double crossover between two homologous regions that flank the modification and the corresponding region on the chromosome. This natural form of genetic transformation is common in Streptococcus pneumoniae (S. pneumoniae) [28] and Bacillus subtilis (B. subtilis) [29]. For example, direct homologous integration of a thermosensitive plasmid into the L. lactis chromosome carrying a chromosomal DNA fragment ( $\geq 500 \mathrm{bp}$ ) was achieved by sequential recombination of two fragment flanking modifications, such as nucleotide changes and DNA deletions or insertions [30]. This thermosensitive plasmid vector might be cured during several generations at $37^{\circ} \mathrm{C}$; therefore, it might be useful for selecting foodgrade mutants containing a single insertion element (e.g., a new DNA fragment) in the genome [31].

\section{Therapeutic applications}

Whenever food is ingested, the gastrointestinal tract is exposed to environmental microbes (including probiotics or pathogens). Diseases of the gastrointestinal tract may be caused by invasion of harmful bacteria or pathogens. However, colonization of the human intestine by LAB has probiotic effects that benefit health by improving the balance between "good" and "bad" bacteria in the intestine [32]. Interestingly, some LAB strains may also be adapted to act as therapeutic microorganisms [33]. There are many diseases of the gastrointestinal tract; among these, the global incidence of CRC is continuing to increase [34,35]. Chemotherapeutic regimens are used routinely to treat advanced-stage colon cancer; however, the response rates are poor, and the treatments have adverse side effects [35,36]. Therefore, novel therapeutic or preventive agents with minimal or no side effects are required urgently. $\mathrm{LAB}$ are potential novel therapeutics that can be used to treat CRC; the location of these bacteria places them in a prime position to target CRC, thereby directly or indirectly preventing or treating the disease [37-39]. Many studies have used genetically modified LAB to improve their therapeutic capacity against CRC. For example, Cell Biotech have developed a genetically modified strain of Pediococcus pentosaceus, SL4 ( $P$. pentosaceus SL4), which secrets the LAB-derived anti-cancer protein p8; a previous study demonstrates significant suppression of CRC after oral administration to a mouse xenograft model [40]. In addition, we successfully constructed a mammalian expression vector harboring the p8 gene for use as a vehicle for gene therapy [41]. The advantage of these approaches is that LAB-derived proteins are both beneficial and safe for humans [42]. A study by de Moreno de LeBlanc et al. suggests that oral administration of a catalase-producing Lactococcus lactis (L. lactis) protects mice from chemically induced CRC [43], whereas another study shows that localized delivery of therapeutic doses of interleukin (IL)-10 by genetically engineered L. lactis results in a $50 \%$ reduction in the incidence of colitis in mice, suggesting a potential treatment for inflammatory bowel disease [44]. In addition, Steidler et al. reported improved delivery of IL-10 via $L$. lactis using a bio-containment system based on genomic integration, in which the $I L-10$ gene was replaced by the thymidylate synthase gene (thyA) [45]. Increasing evidence suggests that genetic modification of LAB improves their health-promoting properties and their ability to protect against gastrointestinal diseases; furthermore, genetic modification means that LAB can be targeted to specific diseases with few, if any, toxic side effects.

\section{Conclusions}

Current cancer therapies have limited efficacy because they are highly toxic to both cancer cells and normal tissue. A growing body of evidence suggests that LAB have chemopreventive effects, even though the magnitude of these effects (therapeutic activity) does not match that of chemical drugs. However, LAB can be used as a natural adjuvant for chemotherapy, and they can be engineered to deliver therapeutic payloads in a targeted manner. Many creative approaches have been used to exploit natural bacterial processes and/or to harness bacteria as therapy vectors and cancer cell destroyers. Some of the safety concerns associated with genetic engineering need to be overcome; however, we believe that $\mathrm{LAB}$ are an important new weapon in the fight against cancer and other immune diseases.

\section{Acknowledgments}

This study was supported by the World Class 300 Project, funded by the Small and Medium Business Administration [SMBA, S2367890 (S2416714)], Korea.

\section{Author contributions}

Byung Chull An: Organizing and manuscript writing.

Yongku Ryu: Benefits of probiotics.

Oksik Choi: Application of DDS on LAB.

Sunwoong Hong: Anti-cancer activity of LAB.

Jin Young Heo: Genetic engineering of LAB.

Myung Jun Chung: Supervisor of this study.

\section{Competing interest}

The authors have no conflict of interests to declare.

\section{References}

1. Fuller R (1991) Probiotics in human medicine. Gut 32: 439-42. [Crossref]

2. Saarela M, Mogensen G, Fonden R, Matto J, Mattila-Sandholm T (2000) Probiotic bacteria: safety, functional and technological properties. J Biotechnol 84: 197-215.

3. Quigley EM (2011) Gut microbiota and the role of probiotics in therapy. Curr Opin Pharmacol 11: 593-603. [Crossref]

4. DuPont AW, DuPont HL (2011) The intestinal microbiota and chronic disorders of the gut. Nat Rev Gastroenterol Hepatol 8: 523-531.

5. An BC, Ryu Y, Hong S, Kwon D, Chung MJ (2020) Probiotics as potential therapeutics for colorectal cancer. Am J Biomed Sci \& Res 9: AJBSR.MS.ID.001262.

6. Yadav NR, Bhitre MJ, Ansari IK, Ansari IK (2013) Probiotic delivery systems: applications, challenges and prospective. Int Res J Pharmacy 4. 
7. Zhong L, Zhang X, Covasa M (2014) Emerging roles of lactic acid bacteria in protection against colorectal cancer. World $J$ Gastroenterol 20: 7878-7886.

8. Nazir Y, Hussain SA, Hamid AA, Song Y (2018) Probiotics and their potential preventive and therapeutic role for cancer, high serum cholesterol, and allergic and HIV diseases. Biomed Res Int 29: 3428437.

9. Shmuely H, Domniz N, Cohen D (2013) Probiotics in the prevention of colorectal cancer. Curr Colorectal Cancer Rep 9: 31-36.

10. Nami Y, Haghshenas B, Haghshenas M, Abdullah N, Khosroushahi AY (2015) The Prophylactic effect of probiotic Enterococcus lactis IW5 against different human cancer cells. Front Microbiol 6: 1317

11. Al-Dujaili E, Bajes H (2019) Probiotics and biotechnology advances in reducing and preventing colorectal cancer; Minireview. Jordan J Pharm Sci 12: 39-48.

12. Chong ESL (2014) A potential role of probiotics in colorectal cancer prevention: review of possible mechanisms of action. World J Microbiol Biotechnol 30: 351-374.

13. De Oliveira Carvalho RD, do Carmo FLR, de Oliveira Junior A, Langella P, Chatel JM, et al. (2017) Use of wild type or recombinant lactic acid bacteria as an alternative treatment for gastrointestinal inflammatory diseases: A focus on inflammatory bowel diseases and mucositis. Front Microbiol 8: 800.

14. Payne J, MacCormick CA, Griffin HG, Gasson MJ (1996) Exploitation of a chromosomally integrated lactose operon for controlled gene expression in Lactococcus lactis. FEMS Microbiol Lett 136: 19-24.

15. Sanders JW, Venema G, Kok J (1997) A chloride-inducible gene expression cassette and its use in induced lysis of Lactococcus lactis. Appl Environ Microbiol 63: 4877 4882 .

16. Nauta A, van Sinderen D, Karsens H, Smit H, Venema G, et al. (1996) Inducible gene expression mediated by a repressor-operator system isolated from Lactococcus lactis bacteriophage rlt. Mol Microbiol 19: 1331-1341.

17. Madsen SM, Arnau J, Vrang A, Givskov M, Israelsen H (1999) Molecular characterization of the $\mathrm{pH}$-inducible and growth phase-dependent promoter $\mathrm{P} 170$ of Lactococcus lactis. Mol Microbiol 32: 75-87.

18. O'Sullivan DJ, Walker SA, West SG, Klaenhammer TR (1996) Development of an expression strategy using a lytic phage to trigger explosive plasmid amplification and gene expression. Biotechnology 14: 82-87.

19. Levander F, Svensson M, Rådström P (2002) Enhanced exopolysaccharide production by metabolic engineering of Streptococcus thermophilus. Appl Environ Microbiol 68: 784-790.

20. Leenhouts KJ, Tolner B, Bron S, Kok J, Venema G, et al. (1991) Nucleotide Sequence and Characterization of the Broad-Host-Range Lactococcal Plasmid pWVO1. Plasmid 26: 55-66.

21. von Wright A, Raty K (1993) The nucleotide sequence for the replication region of pVS40, a lactococcal food grade cloning vector. Lett Appl Microbiol 17: 25-28.

22. Hayes F, Vos P, Fitzgerald GF, de Vos WM, Daly C (1991) Molecular organization of the minimal replicon of novel, narrow-host range, lactococcal plasmid pC1305. Plasmid 25: 16-26.

23. Biet F, Cenatiempo Y, Fremaux C (1999) Characterization of pFR18, a small cryptic plasmid from Leuconostoc mesenteroides ssp. mesenteroides FR52, and its use as a food grade vector. FEMS Microbiol Lett 179: 375-383.

24. Ahmed FE (2003) Genetically modified probiotics in foods. Trends Biotechnol 21: 491497.
25. Hols P, Defrenne C, Ferain T, Derzelle S, Delplace B, et al. (1997) The alanine racemase gene is essential for growth of Lactobacillus plantarum. J Bacteriol 179: 3804-3807.

26. Mignon C, Sodoyer R, Werle B (2015) Antibiotic-free selection in biotherapeutics: now and forever. Pathogens 4: 157-181.

27. Renault P (2002) Genetically modified lactic acid bacteria: applications to food or health risk assessment. Biochimie 84: 1073-1087.

28. Campbell EA, Choi SY, Masure HR (1998) A competence regulon in Streptococcus pneumoniae revealed by genomic analysis. Mol Microbiol 27: 929-939.

29. Dubnau D, Lovett CM (2002) Transformation and recombination. In Bacillus subtilis and its closest relatives: from gene to cells. pp. 453-471, ASM Press.

30. Biswas I, Gruss A, Ehrlich SD, Maguin E (1993) Higah efficiency gene inactivation and replacement system for gram-positive bacteria. J Bacteriol 175: 3628-3635.

31. Maguin E, Prévost H, Ehrlich SD, Gruss A (1996) Efficient insertional mutagenesis in lactococci and other gram-positive bacteria. J Bacteriol 178: 931-935.

32. DuPont AW, DuPont HL (2011) The intestinal microbiota and chronic disorders of the gut. Nat Rev Gastroenterol Hepatol 8: 523-531.

33. Quigley EM (2011) Gut microbiota and the role of probiotics in therapy. Curr Opin Pharmacol 11: 593-603.

34. Cunningham D, Atkin W, Lenz HJ, Lynch HT, MinskyB (2010) Colorectal cancer Lancet 375: 1030-1047.

35. Rabik CA, Dolan ME (2007) Molecular mechanisms of resistance and toxicity associated with platinating agents. Cancer Treat Rev 33:9-23.

36. Macdonald JS, Astrow AB (2001) Adjuvant therapy of colon cancer. Semin Oncol 28:30-40.

37. Yang Y, Xia Y, Chen H, Hong L, Feng J, et al. (2016) The effect of perioperative probiotics treatment for colorectal cancer: short-term outcomes of randomized controlled trial. Oncotarget 7: 8432-8440.

38. Cousin FJ, Jouan-Lanhouet S, Théret N, Brenner C, Jouan É, et al. (2016) The probiotic Propionibacterium freudenreichii as a new adjuvant for TRAIL-base therapy in colorectalcancer. Oncotarget 7: 7161-7178.

39. Hendler R, Zhang Y (2018) Probiotics in the treatment of colorectal cancer. Medicine (Basel) 5: 1-14.

40. An BC, Ryu Y, Yoon YS, Choi O, Park HJ, et al. (2019) Colorectal cancer therapy using a Pediococcus pentosaceus SL4 drug delivery system secreting lactic acid bacteriaderived protein p8. Mol Cells 30: 755-762.

41. An BC, Hong S, Park HJ, Kim BK, Ahn JY, et al. (2019) Anti-colorectal cancer effects of probiotic-derived $\mathrm{p} 8$ protein. Genes 10: 624 .

42. Steidler L, Vandenbroucke K (2006) Genetically modified Lactococcus lactis: novel tools for drug delivery. International journal of dairy technology 59: 140-146.

43. de Moreno de LeBlanc A, LeBlanc JG, Perdigón G, Miyoshi A, Langella P, et al (2008) Oral administration of a catalase-producing Lactococcus lactis can prevent a chemically induced colon cancer in mice. J Med Microbiol 57: 100-105.

44. Steidler L, Hans W, Schotte L, Neirynck S, Obermeier F, et al. (2000) Treatment of murine colitis by Lactococcus lactis secreting minterleukin-10. Science 25: 1352-1355.

45. Steidler L, Neirynck S, Huyghebaert N, Snoeck V, Vermeire A, et al. (2003) Biological containment of genetically modified Lactococcus lactis for intestinal delivery of human interleukin 10. Nat Biotechnol 21: 785-787.

Copyright: (C)2020 An BC. This is an open-access article distributed under the terms of the Creative Commons Attribution License, which permits unrestricted use, distribution, and reproduction in any medium, provided the original author and source are credited. 